\title{
Aplicação de transglutaminase microbiana em produtos cárneos processados com teor reduzido de sódio
}

\author{
Application of microbial transglutaminase in processed \\ meat products with reduced content of sodium \\ Rosiane Costa Bonfim ${ }^{{ }^{*}}$ Jessica da Silva Machado
Simone Pereira Mathias ${ }^{\mathrm{I}}$ Amauri Rosenthal ${ }^{\mathrm{II}}$
}

- Revisão Bibliográfica -

\section{RESUMO}

\begin{abstract}
O presente artigo compreende uma revisão sobre a aplicação da transglutaminase de origem microbiana (MTGase) em produtos cárneos, elaborados com teor reduzido de sódio. A MTGase tem se mostrado muito eficiente em promover pontes cruzadas entre proteinas, favorecendo a coesão em produtos reestruturados e melhorando a força de géis em produtos cárneos emulsionados, contribuindo para a melhoria de textura e preservando o sabor dos produtos. Tradicionalmente, o cloreto de sódio ( $\mathrm{NaCl}$ ) é adicionado às massas cárneas por desempenhar um papel-chave na solubilização das proteinas miofibrilares. No entanto, o excesso desse mineral tem sido associado aos altos indices de problemas de saúde, como a hipertensão arterial. Como reação a este cenário, a sociedade cientifica e indústrias ligadas ao setor cárneo têm buscado alternativas que possam atuar na redução do sódio nesses alimentos. Na presente revisão, são relatados estudos recentes sobre a aplicação da MTGase em diversos produtos de origem cárnea, elucidando a importância desse coadjuvante de tecnologia para a pesquisa cientifica e a aplicação industrial na área de produção de alimentos de conveniência e mais saudáveis.
\end{abstract}

Palavras-chave: "fabricantes de estrutura", pontes-cruzadas, redução de sódio.

\section{ABSTRACT}

This article includes a review of the application of microbial transglutaminase (MTGase) in meat products prepared with reduced-sodium. The MTGase has shown to be very efficient in promoting protein cross-bridges, favoring the cohesion restructured products and improving the strength of gels inemulsified meat products, contributing to preserve and improve their texture and flavor. Traditionally sodium chloride ( $\mathrm{NaCl}$ ) is added to pasta cárneas to play a key role in the solubilization of the myofibrillar proteins. However, the excess of this mineral has been linked to high rates of health problems as hypertension. In response to this scenario, scientific society and industries connected to the meat industry has sought alternatives that can acte to reduce the sodium in these foods. In this review, recent studies are reported on the application of MTGase in various products of meat mixture, elucidating the importance of supporting technology for scientific research and industrial application in the production of convenience healthier foods.

Key words: "structure makers", cross-link, sodium reduction.

\section{INTRODUÇÃO}

A comunidade científica e industrial no setor cárneo vem investindo no desenvolvimento de novos produtos que atendam à demanda de produtos de fácil preparo e que sejam saudáveis. Da mesma forma, tem investido em tecnologias que maximizem a utilização de todas as partes das carcaças, reduzindo as perdas.

Assim, na busca de melhorar as propriedades das proteínas cárneas e aumentar o aproveitamento de aparas de cortes cárneos, a indústria, ao longo dos anos, vem usando uma ampla gama de aditivos, como o cloreto de sódio $(\mathrm{NaCl})$, que possui a capacidade de solubilizar as proteínas miofibrilares.

Os sais influenciam na hidratação de proteínas, aumentando a capacidade de retenção de água e, por consequência, melhora a textura e rendimento dos processos (ROCHA GARCIA et al., 2010).

Desta forma, significativa parcela do sódio presente na dieta provém de alimentos industrializados

\footnotetext{
'Departamento de Tecnologia de Alimentos (DTA), Universidade Federal Rural do Rio de Janeiro (UFRRJ), 23890-000, Seropédica, RJ, Brasil. E-mail: rcostabonfim@yahoo.com.br. *Autor para correspondência.

"Embrapa Agroindústria de Alimentos, Guaratiba, RJ, Brasil.
} 
e, dentre esses, destacam-se os derivados cárneos. Nesses produtos, além da palatabilidade oriunda do gosto salgado, o cloreto de sódio é responsável pelo desenvolvimento de propriedades funcionais e influencia de forma decisiva sua estabilidade e conservação (DESMOND, 2006).

Porém, muitos trabalhos têm sido realizados sobre a redução de sódio na fabricação de alimentos, devido ao excesso na ingestão deste mineral estar intimamente ligada ao desenvolvimento de doenças crônicas, como hipertensão arterial e doenças cardiovasculares.

No entanto, a redução de sódio enfrenta grande complexidade no segmento cárneo, pois, além de prover palatabilidade, o $\mathrm{NaCl}$ é responsável por diversas propriedades funcionais (ROCHA GARCIA et al., 2013).

A busca por alternativas para redução do uso de $\mathrm{NaCl}$, sem prejuízo para a qualidade dos produtos, mantendo a aceitação e consumo dos derivados cárneos, constitui grande desafio para a indústria.

Nesse sentido, uma maneira de melhorar as propriedades funcionais das proteínas cárneas e consequentemente otimizar os processos de fabricação é o uso de enzimas que têm a capacidade de catalisar reações entre proteínas, as chamadas structuremakers ("fabricantes de estruturas"). Dentro dessa classe de enzimas, capazes de "fabricar estrutura", destacam-se as transglutaminases, sobretudo as produzidas a partir de microrganismo, as MTGases (WEISS et al., 2010).
As MTGases têm sido utilizadas com sucesso para melhorar as propriedades físicas de produtos cárneos, por catalisar reações aciltransferase entre grupos $\gamma$ - carboxiamida de pepitídeos, ligados a resíduos de glutamina e várias aminas primárias. Essa enzima forma ligação de isopeptídeos entre glutamina e resíduos de lisina em proteínas, introduzindo, assim, ligações covalentes cruzadas intra e intermoleculares (KURAISHI et al., 2001).

Em razão da importância do tema, este trabalho teve por objetivo revisar as aplicações tecnológicas da enzima MTGase como aditivo auxiliador na redução do uso de cloreto de sódio em produtos cárneos.

Modo de ação e modificações estruturais ocasionadas pela MTGase

As reações induzidas pela MTGase nas ligações das proteínas da carne são de grande importância, pois promovem melhoria da qualidade da textura de produtos formulados a base de carne e resultam em benefícios econômicos consideráveis (AHHMED et al., 2009).

A MTGase é uma transferase que catalisa reações de acil-transferência entre um grupo $\gamma$-carboxiamida de resíduos de glutamina e diversas aminas primárias, incluindo poliaminas. Ela pode atuar de três formas distintas em proteínas (Figura 1): a) entre resíduos de glutamina e aminas livres; b) entre resíduos de glutamina e lisina; e c) entre resíduos de glutamina

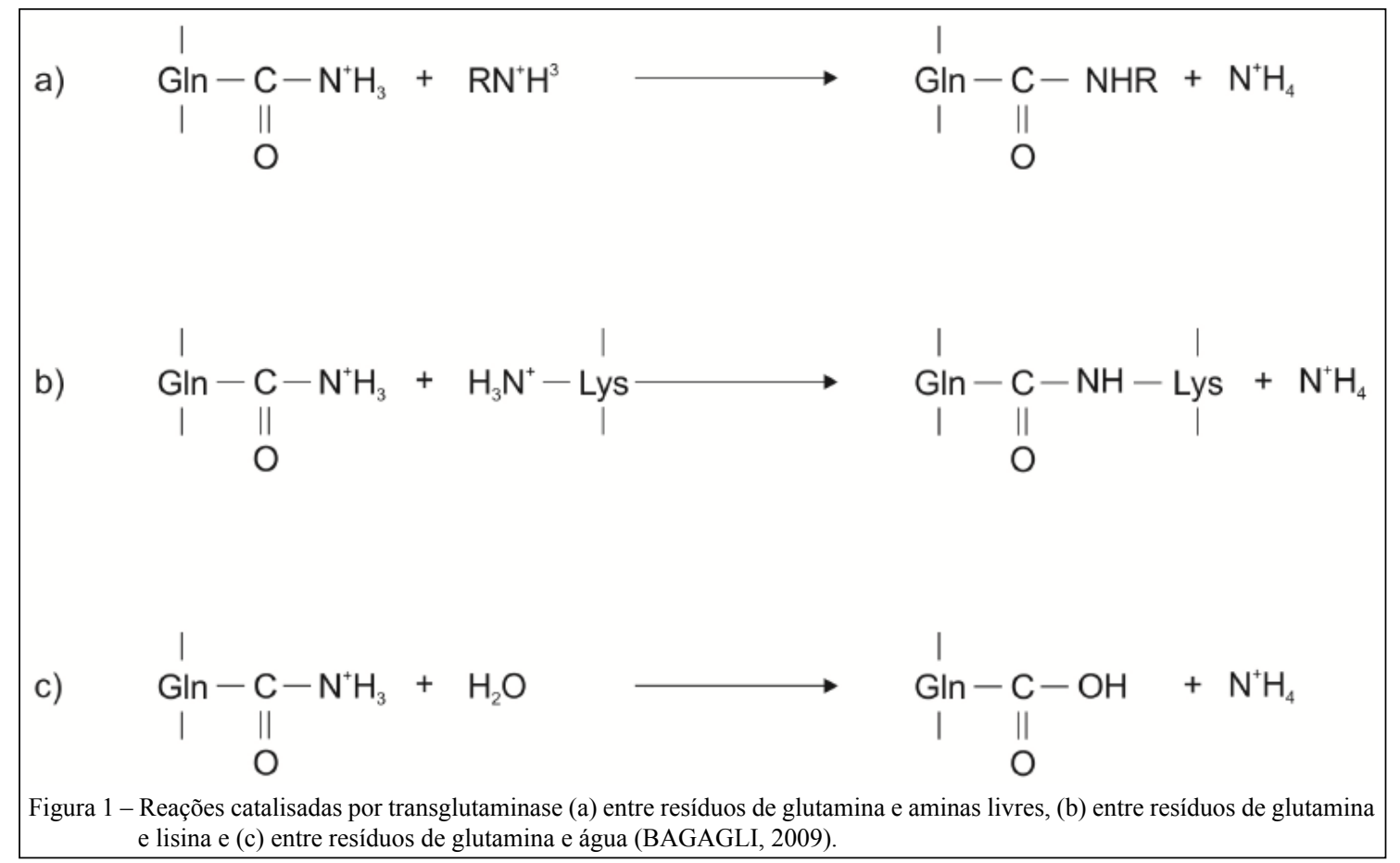

Ciência Rural, v.45, n.6, jun, 2015. 
e água (BAGAGLI, 2009; AHHMED et al., 2009; CHANARAT et al., 2012).

O mecanismo de ação da transglutaminase é muito semelhante ao de proteases (PLACIDO et al., 2008), consistindo basicamente em duas etapas (Figura 2). Na primeira etapa, o grupo tiol da cisteína, presente no sítio ativo, ataca a cadeia lateral de um resíduo de glutamina disponível no substrato proteico, formando um complexo acil-enzima e liberando amônia. Em seguida, uma amina primária substitui a enzima, gerando uma glutamina carboxiamida modificada (NEGUS, 2001).

SegundoAHHMEDetal.(2009), opotencial catalítico da MTGase, é capaz de promover interação entre as cadeias laterais de glutamina (C-terminal) com as cadeias laterais de lisina ( $\mathrm{N}$-terminal). Assim, a MTGase catalisa as interconexões de miofibrilas, criando polímeros gigantes, melhorando a elasticidade do gel cárneo e, a partir de ligações proteína-proteína, forma uma rede proteica.

AHHMED et al. (2009) pesquisaram a atuação da MTGase em carne de frango e bovina e concluíram que os músculos branco e vermelho responderam de forma diferente e, diante dos resultados, levantaram quatro fatores que podem ser relacionados: (a) variação da fisiologia muscular e morfogenese, (b) a identidade de aminoácidos livres, especialmente aqueles com a capacidade de reagir com o MTGase, (c) a quantidade e a distância transferíveis entre aminoácidos e (d) o valor de inibidores da MTGase.
Aplicação na reestruturação de carnes

Carnes reestruturadas estão se tornando cada vez mais populares e possuem inúmeras vantagens para indústria cárnea (SERRANO et al., 2004; BONFIM, 2013). A demanda pela qualidade de produtos cárneos, com preços acessíveis, tem o pré-requisito para o desenvolvimento de métodos de reestruturação de cortes de baixo valor nutritivo e pior qualidade, visando a melhorar seu valor de mercado, a fim de favorecer a produção de bifes palatáveis, semelhantes ao músculo intacto, e maximizar a eficiência da carcaça utilizada (CESTARI et al., 2007; BUCHERT et al., 2010).

Convencionalmente, o cloreto de sódio e o fosfato, aliados ao tratamento térmico, têm sido utilizados para ligar pedaços de carnes em conjunto (GHAVIMI et al., 1987) e os produtos crus são, normalmente, congelados para melhor agregação (SEIDEMAN \& DURLAND, 1983).

A técnica de reestruturação de aparas, auxiliada pela MTGase, tem se tornado uma ferramenta de grande importância no setor de carnes, sendo utilizada para melhorar a textura de proteínas de carne reestruturada, com ou sem adição de sal e fosfatos (SERRANO et al., 2004).

DIMITRAKOPOULOU et al. (2005) estudaram a utilização da MTGase (Activa ${ }^{\circledR} \mathrm{WM}$ ) em reestruturado cozido, a base de carne suína, e puderam observar que a inclusão de $0,15 \%$ de enzima foi o suficiente para formular um produto livre de fosfatos e com teor reduzido de sal (1\%), resultando num produto mais saudável e sensorialmente aceitável.

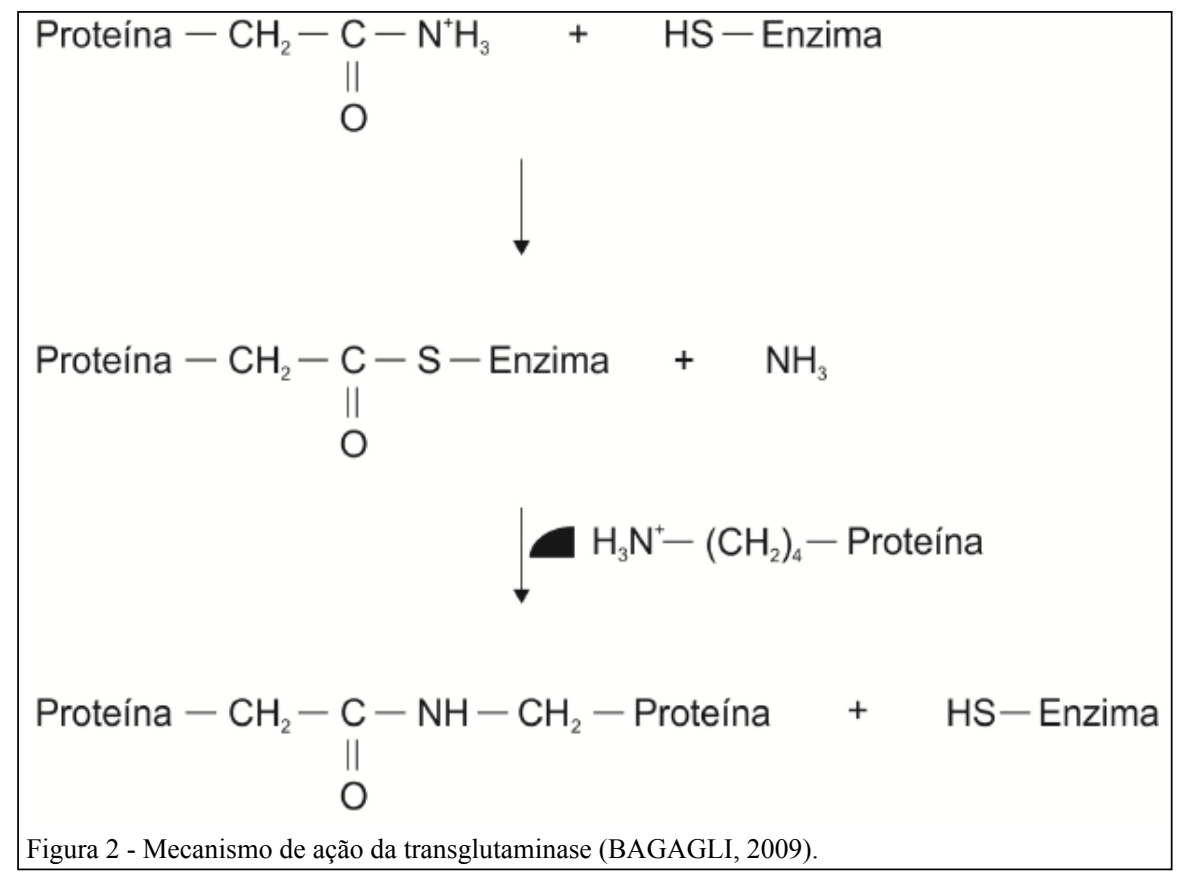

Ciência Rural, v.45, n.6, jun, 2015. 
No mesmo sentido, ÁVILA et al. (2010) desenvolveram um estudo sobre a aplicação de MTGase (Activa ${ }^{\circledR}$ ) na reestruturação de pernil suíno desossado para fabricação de presunto seco curado com nível reduzido de sal. Eles puderam concluir que a enzima pode ser utilizada numa escala prática na reestruturação de pernil suíno, por estabelecer ligações cruzadas estáveis durante os processos de salga e secagem.

CAMARGO (1999) relatou que níveis crescentes de MTGase, até $1,5 \%$, apresentaram eficiência na reestruturação de aparas de carne de peru, apresentando melhor textura, com consequente menor resistência ao corte e maior suculência nos tratamentos onde houve compressão da massa cárnea durante a ativação enzimática.

KILLIC (2003) estudou o efeito da adição da enzima MTGase em döner kebab de frango e verificou que houve uma reação de ligação cruzada entre as proteínas da carne, sendo a enzima uma fonte de substituição potencial para o cloreto de sódio.

Em reestruturado de carne de aves com níveis de sal reduzido, elaborados com algas e aplicação de MTGase e caseinato, a MTGase, em conjunto com o caseinato, mostrou-se eficiente em promover a reticulação entre proteínas, resultando em um produto sensorialmente aceitável e estável no armazenamento (CONFRADES et al., 2011).

CESTARI (2007) estudou a valorização de músculos provenientes da paleta bovina, pela ação da MTGase (Activa ${ }^{\circledR}$ TG-B) por meio de injeção de salmoura e posterior massageamento e concluindo que a MTGase é efetiva no processo de ligação entre os fragmentos de carne. Essa propriedade é essencial para a textura do produto, independentemente do processo de incorporação da enzima utilizado, trazendo aos bifes reestruturados boa qualidade sensorial.

FERREIRA et al. (2012), comparando as características físico-químicas e sensoriais de hambúrguer bovino elaborado com cloreto de sódio, polifosfato e MTGase, reconheceram a vantagem em se utilizar a MTGase em detrimento dos outros aditivos comumente empregados para unir os pedaços cárneos, cloreto de sódio e polifosfatos. A enzima foi capaz de promover a junção dos pedaços de carne, aumentando o rendimento e mantendo a suculência, mostrando ser uma alternativa para a obtenção de reestruturados crus sobre refrigeração e resultando em produtos saudáveis, com teores menores de sais, como os polifosfatos e cloreto de sódio.

Além de contribuir na elaboração de formulações com teor reduzido de sódio, a MTGase tem sido estudada recentemente em relação a sua atuação em conjunto com outras tecnologias de processamento. Nesse contexto, BONFIM (2013) avaliou a ação em conjunto da MTGase com a tecnologia de alta pressão hidrostática (APH) na fabricação de reestruturado de carne bovina e, em relação à ação sinérgica, pôde observar que a pressão faz com que o núcleo hidrófobo da proteína se torne mais exposto e, portanto, mais facilmente disponível para a ação MTGase.

Esses estudos são de grande importância por contribuir para o desenvolvimento de produtos mais saudáveis, com menor quantidade de aditivos, estáveis e seguros. Aplicação na fabricação de produtos cárneos
emulsionados

A fabricação de produtos emulsionados a base de carnes fragmentadas envolve a ação mecânica sobre a carne na presença de $\mathrm{NaCl}$, o qual extrai e solubiliza as proteínas miofibrilares. Dessa forma, a proteína envolve a gordura, formando uma estrutura de gel estabilizada, resultando num produto com bom rendimento (ROÇA, 2000). No entanto, é crescente a busca por produtos mais saudáveis e com menor teor de gordura e sal.

Nesse contexto, crescem as pesquisas da enzima MTGase, por atuar na estrutura do gel em produtos emulsionados, tornando possível a redução de cloreto de sódio, fosfatos e gordura (COLMENERO et al., 2005).

MUGURUMA et al. (2003) avaliaram a funcionalidade de MTGase e os seus efeitos sobre as propriedades de gelificação em salsichas de frango com um nível baixo de fosfato, e observaram que a textura foi melhorada pela formação de uma estrutura de rede, o que contribuiu para a dureza de géis a base de carne com biopolímeros adicionados.

A formação de gel, induzida pela adição de MTGase em produtos a base de carne, tem sido investigada por muitos pesquisadores, onde a força do gel é reforçada pelo calor no tratamento subsequente à ação de MTGase, aprimorando a resistência do gel de proteínas e a textura de carne e seus derivados (AHHMED et al., 2009).

Colmenero et al (2005) desenvolveram uma salsicha suína (salsicha tipo Frankfurt) com teor reduzido de sódio e MTGase e compararam os efeitos da MTGase com outros ingredientes não cárneos (caseinato, $\mathrm{KCl}$ e fibra de trigo). Concluíram que, embora a MTGase individualmente seja eficiente na formação do gel, a sua combinação com os demais ingrediente testados foi a melhor alternativa em relação a características físico-químicas próximas aos produtos com teores normais de cloreto de sódio. 
SUN \& ARNFILLD (2011) estudaram a formação de gel da carne de frango com MTGase e concluiram queaMTGase tempotencial para proporcionar novas oportunidades de expandir a utilização de carne de baixo valor em produtos alimentícios.

Da mesma forma que para produtos reestruturados, também tem sido estudada a ação conjunta da MTGase com APH na formação de géis a base de carne. TRESPALACIOS \& PLÁ (2007) verificaram a ação simultânea da enzima com essa tecnologia de processamento não térmica na formação de gel em proteínas de carne de frango e puderam concluir que a APH possibilitou a interação de proteínas miofibrilares com globulares por ação da MTGase, com níveis baixo de gordura e sal, o que não acontece em pressão atmosférica.

Recentemente, pesquisas com a combinação da condição de $\mathrm{pH}$ extremo $(1,5$ e 12,0$)$ combinado à MTGase têm mostrado que o desdobramento estrutural das proteínas pelos tratamentos com $\mathrm{pH}$ extremo favorece a ação da enzima por promover maior acessibilidade ao substrato, glutamina e lisina, aumentando a capacidade de formar gel em massas a base de proteínas miofibrilares de carne suína (JIANG \& XIONG, 2013).

\section{CONCLUSÃO}

Este artigo de revisão destacou os avanços na aplicação da enzima MTGase em produtos cárneos, mostrando que a MTGase é um aditivo de grande potencial na indústria cárnea, na formulação de produtos mais saudáveis e também na reformulação de produtos clássicos. Assim, a reticulação de proteínas em produtos cárneos por meio de uso da enzima MTGase favorece a formulação de novos produtos, tendo como resultado um maior aproveitamento das matérias-primas e melhoramento da textura, viabilizando a fabricação de produtos com redução de sódio, sem alterar as suas propriedades sensoriais.

\section{REFERÊNCIAS}

AHHMED, A.M. et al. Dependence of microbial transglutaminase on meat type in myofibrillar proteins cross-linking. Food Chemistry, v.112, p.354-361, 2009. Disponível em: <http:// www-sciencedirect-com.ez30.periodicos.capes.gov.br/science/ article/pii/S030881460800633X > . Acesso em 16 nov 2012. doi: 10.1016/j.foodchem.2008.05.078

AVILA, M.D.R. et al. Microbial transglutaminase for cold-set binding of unsalted/salted pork models and restructured dry ham. Meat Science, v.84, p. $747=754,2010$. Disponível em: <http:// www.sciencedirect.com/science/article/pii/S0309174009003726>. Acesso em: 12 abr. 2013. doi: 10.1016/j.meatsci.2009.11.011.
BAGAGLI, M.P. Produção de transglutaminase de Streptomyces sp. P20, caracterização e aplicação da enzima bruta. 2009. 113f. Dissertação (Mestrado em Ciência de Alimentos) - Universidade Estadual de Campinas, Faculdade de Engenharia de Alimentos, Campinas, SP.

BONFIM, R.C. Aplicação de transglutaminase microbiana e alta-pressão hidrostática (APH) em produto cárneo reestruturado bovino. 2013. 66f. Dissertação (Mestrado em Ciência e Tecnologia de Alimentos) - Universidade Federal Rural do Rio de Janeiro, Seropédica. RJ.

BUCHERT, J. et al. Crosslinking Food Proteins for Improved Functionality. Annual Review of Food Science and Technology. v. 1, p.113-138, 2010. Disponível em: $<$ http://www.annualreviews. org/doi/abs/10.1146/annurev.food.080708.100841>. Acesso em: 16 nov 2012. doi: 10.1146/annurev.food.080708.100841.

CAMARGO, P.J.C.C. Influência da Transglutaminase (ACTIVA $^{\circledR}$ TG-B) e de Parâmetros de Processo na Textura de um Reestruturado Empanado de Carne de Peru. 1999. 86f. Dissertação (Mestrado em Tecnologia de Alimentos) - Faculdade de Engenharia de Alimentos, Universidade Estadual de Campinas, Campinas, SP.

CESTARI A.L. Carne bovina reestruturada com transglutaminase: desenvolvimento e determinações de cor e textura. 2007. 88f. Dissertação (Mestrado em Engenharia de Alimentos) - Faculdade de Engenharia de Alimentos, Universidade Estadual de Campinas, SP.

CHANARAT, S. et al. Comparative study on protein crosslinking and gel enhancing effect of microbial transglutaminase on surimi from different fish. Journal of the Science of Food and Agriculture, v.92, n.4, p.844-852, 2012. Disponível em: $<$ http://www.wileyonlinelibrary.com>. Acesso em: 02 jan 2013. doi:10.1002/jsfa.4656.

COLMENERO, F.J. et al. Physicochemical properties of low sodium frankfurter with added walnut: effect of transglutaminase combined with caseinate, $\mathrm{KCl}$ and dietary fibre as salt replacers. Meat Science, v.69, n.4, p.781-788, 2005. Disponivel em: $<\mathrm{http}: / /$ www.ncbi.nlm.nih.gov/pubmed/22063157>. Acesso em: 14 mar 2013. doi: 10.1016/j.meatsci.2004.11.011.

COFRADES, S. et al. Quality characteristics of low-salt restructured poultry with microbial transglutaminase and seaweed. Meat Science, v.87, p.373-380, 2011. Disponível em: <http:// www.sciencedirectcom.ez29.periodicos.capes.gov.br/science/ article/pii/S0309174010004067>. Acesso em: 26 abr 2013. doi: 1-s2.0-S03091740100004067.

DESMOND, E. Reducing salt: a challenge for the meat industry. Meat Science, v.74, p.188-196, 2006. Disponível em: <http:// www-sciencedirect-com.ez30.periodicos.capes.gov.br/science/ article/pii/S0309174006001161>. Acesso em: 26 abr 2013. doi: 10.1016/j.meatsci.2006.04.014.

DIMITRAKOPOULOU, M.A. et al. Effect of salt and transglutaminase (TG) level and processing conditions on quality characteristics of phosphate-free, cooked, restructured pork shoulder. Meat Science, v.70, p.743-749, 2005. Disponivel em: $<$ http://www-sciencedirectcom.ez30.periodicos.capes.gov.br/ science/article/pii/S0309174005001130>. Acesso 09 out 2012. doi: 10.1016/j.meatsci.2005.03.011.

FERREIRA, M.S. et al. Comparação das características físicoquímicas e sensoriais de hambúrgueres de carne bovina elaborados 
com cloreto de sódio, polifosfato e transglutaminase. Revista Brasileira de Medicina Veterinária, v.34, n.1, p.52-60, 2012. Disponível em: <http://www.rbmv.com.br/pdf_artigos/13-062012 12-32RBMV\%20010.pdf>. Acesso em: 10 jan. 2013.

GHAVIMI, B. et al. Effects of tumbling at various speeds on some characteristics of restructured cured beef. Journal of Food Science, v.52,n.3,p.543-544,553, 1987. Disponívelem: $<$ http://onlinelibrary. wiley.com/doi/10.1111/j.1365-2621.1987.tb06670.x/pdf >. Acesso em: 16 mar 2013. doi: 10.1111/j.1365-2621.1987.tb06670.x

JIANG, J.; XIONG, Y.L. Extreme $\mathrm{pH}$ treatments enhance the structure-reinforcement role of soy protein isolate and its emulsions in pork myofibrillar protein gels in the presence of microbial transglutaminase. Meat Science, v.93, p.469-476, 2013. Disponível em: <http://www-sciencedirect-com.ez30.periodicos. capes.gov.br/science/article/pii/S0309174012003634>. Acesso em: 20 jan 2013. doi: 10.1016/j.meatsci.2012.11.002.

KILLIC, B. Effect of microbial transglutaminase and sodium caseinate on quality of chicken döner kebab. Meat Science, v.63. p.417-421, 2003. Disponível em: <http://wwwsciencedirectcom.ez30.periodicos.capes.gov.br/science/article/pii/ S030917400200102X>. Acesso em 23 ago 2012. doi: 10.1016/ S0309-1740(02)00102-X.

KURAISHI, C. et al. Transglutaminase: its utilization in the food industry. Food Reviews International, v.17, n.2, p.221-246, 2001. Disponível em: <http://www.tandfonline.com/doi/abs/10.1081/ FRI-100001258?journalCode=1fri20\#.VHU0sdLF9vk $>$. Acesso em 14 dez 2012. doi: 10.1081 / FRI-100001258.

MUGURUMA, M. et al. Soybean and milk proteins modified by transglutaminase improves chicken sausage texture even at reduce levels of phosphate. Meat Science, v.63, p.191-197, 2003. Disponível em: <http://www-sciencedirect-com.ez30.periodicos. capes.gov.br/science/article/pii/S0309174002000700>. Acesso em: 12 nov 2012. doi: 10.1016/S0309-1740(02)00070-0.

NEGUS, S.S. A novel transglutaminase derived from Streptoversticillium baldaccii. 2001. 108f. Thesis (Doctor Philosophy) - School of Biomolecular and Biomedical Science, Griffth University, Queensland, Australia.

PLACIDO, D. Auto-induction and purification of a Bacillus subtilis transglutaminase (Tgl) and its preliminary crystallographic characterization. Protein Expression and Purification. v.59, p.1-
8, 2008. Disponível em: <http://www-sciencedirect-com.ez30. periodicos.capes.gov.br/science/article/pii/S1046592807003166>. Acesso em: 17 out 2012. doi: 10.1016/j.pep.2007.12.004.

ROCHA GARCIA, C.E.; BOLOGNESI, V. J.; CASTILHO, M. P. ; NASCIMENTO, A. J.; MASSON, M. L.. Rendimento e parâmetros físico-químicos de charque elaborado com soluções salinas de hidrocolóides. In: SIMPÓSIO DE CIÊNCIA E TECNOLOGIA DE ALIMENTOS, 2., 2010, Aracaju, SE. Anais... Aracaju: SBCTASERGIPE, 2010. p.1628-1631.

ROCHA GARCIA, C.E. et al. Aplicações tecnológicas e alternativas para redução do cloreto de sódio em produtos cárneos. B.CEPPA, v.31, n.1, p.139-150, 2013. Disponível em: <http://ojs. c3sl.ufpr.br/ojs2/index.php/alimentos/article/view/32715>. Acesso em: 21 de out 2012

ROCA, R.O. Tecnologia da carne produtos derivados. Botucatu: Faculdade de Ciências Agronômicas, UNESP, 2000. 202p.

SEIDEMAN, S.C.; DURLAND, P.R. Restructured red meat products: in review. Journal of Food Quality. 6, p.81101, 1983. Disponível em: <http://onlinelibrary.wiley.com/ doi/10.1111/j.1745-4557.1983.tb00759.x/abstract>. Acesso em 12 dez 2012. doi: 10.111/j.1745-4557.1983.tb00759.x.

SERRANO, A. Transglutaminase as binding agent in fresh restructured beef steak with added walnuts. Food Chemistry, v.85, n.3, p.423-429, 2004. Disponível em: <http://wwwsciencedirect-com.ez30.periodicos.capes.gov.br/science/article/ pii/S0308814603003716>. Acesso em: 17 dez 2012. doi: 10.1016/j. foodchem.2003.07021.

SUN, D.X.; ARNFIELD, D.S. Gelation properties of chicken myofibrillar protein induced by transglutaminase crosslinking. Journal of Food Engineering, v.107, p.226-233, 2011. Disponível em: <http://link.periodicos.capes.gov.br.ez29.periodicos.capes. gov.br>. Acesso em: 10 jan 2013. doi: 1-s2.0-S0260877411003281.

TRESPALACIOS, P.; PLA, R. Simultaneous application of transglutaminase and high pressure to improve functional properties of chicken meat gels. Food Chemistry, v.100, n.1, p.272, 2007. Disponível em: <http://www-sciencedirect-com.ez30. periodicos.capes.gov.br/science/article/pii/S0308814605008654>. Acesso em: 20 nov 2013. doi: 10.1016/j.foodchem.2005.09.058.

WEISS, J.et al. Advances in ingredient and processing systems for meat and meat products. Meat Science, v.86, p.196-213, 2010. Disponível em: < http://www.sciencedirect.com/science/article/pii/ S0309174010001853>. Acesso em: 23 nov 2012. doi: 10.1016/j. meatsci.2010.05.008. 